\title{
ULTRASTRUCTURAL STUDY OF THE MYCELIAL PHASE OF CLINICAL ISOLATES OF SPOROTHRIX SCHENCKII OBTAINED FROM FELINE, CANINE AND HUMAN CASES OF SPOROTRICHOSIS
}

\author{
Isabel Martins Madrid*, Antonella Souza Mattei, Mauro Pereira Soares, Márcia de Oliveira Nobre, Mário Carlos Araújo \\ Meireles
}

Laboratório de Doenças Infecciosas, Departamento de Veterinária Preventiva, Faculdade de Veterinária, Universidade Federal de Pelotas, Pelotas, RS, Brasil

Submitted: September 30, 2009; Approved: March 14, 2011.

\begin{abstract}
Using transmission electron microscopy, we studied the presence of melanin and cell wall thickness of clinical isolates of Sporothrix schenckii obtained from cats, dogs and humans as compared to reference strains. We detected differences regarding presence of the melanin among the clinical isolates of S. schenckii and a correlation between presence of melanin and cell wall thickness.
\end{abstract}

Key words: conidial, melanin, Sporothrix schenckii, Transmission Electron Microscopy

Sporothrix schenckii is a dimorphic geophilic fungus that causes subcutaneous infection in animals and humans. Classically, infection is caused by traumatic inoculation of soil, plants or organic matter contaminated with the fungus into the body. The infection is normally restricted to lymphatic or fixed cutaneous form in humans and canines; whereas, felines frequently develop the systemic and/or disseminated cutaneous form (15). Various pathogenicity factors such as thermotolerance, extracellular enzymes, composition of the cell wall and presence or absence of melanin are involved in the virulence of this fungus (5).

Melanins are dark brown to black pigments formed by the oxidative polymerization of phenolic and/or indolic compounds and are generally insoluble in water, acids and common organic solvents (1). The presence of melanins has been reported in various pathogenic fungi including Aspergillus fumigatus, Cryptococcus neoformans, Paracoccidioides brasiliensis, Candida albicans, Penicillium marneffei, Fonsecaea pedrosoi, Histoplasma capsulatum and Blastomyces dermatitides (8). Studies with the fungus Sporothrix schenckii have demonstrated the presence of the 1,8dihydroxynaphthalene melanin pentaketide pathway in the mycelial and yeast phases $(10,14)$.

The presence of melanin in the cell walls of various fungi may increase their survival in the environment by providing protection against ultraviolet radiation, desiccation and extreme temperatures. During infection, melanins interfere with the immune response, complement activation and activity of antifungal drugs $(2,6,13)$. Due to the contribution of melanins to fungal virulence, this work evaluated the presence of melanin granules and differences regarding cell wall thickness in clinical isolates of Sporothrix schenckii. 
Nine Sporothrix schenckii clinical isolates from feline, canine and human cases of sporotrichosis were utilized in this study. Two reference strains obtained from Instituto Oswaldo Cruz (Rio de Janeiro, Brazil), IOC1113 and IOC1226, were also used. The isolates were maintained in the Laboratory of Infectious Diseases of the School of Veterinary Medicine at Federal University of Pelotas.

All isolates were inoculated on potato dextrose agar and incubated at $25^{\circ} \mathrm{C}$ for seven days. At the end of the incubation period, samples of S. schenckii cultures were fixed with $2 \%$ glutaraldehyde and $2 \%$ paraformaldehyde in cacodylate buffer, postfixed with $1 \%$ osmium tetroxyde in cacodylate buffer, dehydrated in a graded ethanol series $(30,50,70,90$ and 95\%) and embedded in Epon. Thick sections were stained with methylene blue and selected thin sections were stained with lead citrate and uranyl acetate. The sections were examined with a Zeiss EM 109 transmission electron microscope at 80 kilovolts.

The images obtained by transmission electron microscopy (TEM) were used to determine if there were ultrastructural differences between the cell walls of the clinical isolates de $S$. schenckii obtained from cats, dogs, humans and the two reference strains. The occurrence of melanin was qualitatively evaluated as "absent" or "present". Twenty cells of each strain were measured using Adobe Photoshop 7.0. Differences in cell wall thickness were statistically evaluated with the Tukey's test using the program Statistix 8.0.

TEM demonstrated various degrees of difference in melanin content and cell wall thickness between Sporothrix schenckii isolates obtained from the canine, feline and human clinical cases of sporotrichosis (Table 1). Melanin was detected as electron-dense granules distributed around the cell walls of S. schenckii conidia. The fungal cells were classified into two categories: (1) cells with absence of melanin granules and (2) cells with presence of melanin granules (Fig 1). Analyses of the cell walls revealed that wall thickness ranged from 38.1 to $142.86 \mathrm{~nm}$ in cells devoid of melanin (category 1) and from
63.49 to $250.79 \mathrm{~nm}$ in cells in which melanin was present (category 2). Twenty cells from each sample were analyzed. Significant differences were found among the reference strains and the isolates obtained from dogs, cats and humans, with a $\mathrm{p}$ value $<0.001$ as assessed by the Tukey test (Table 2 ).

Table 1. Results of the analyses of the melanin layer and cell wall thickness of clinical isolates of Sporothrix schenckii.

\begin{tabular}{cccc}
\hline Samples & Origin & Score & Mean \pm SD(nm) \\
\hline IOC1226 & Reference strain & $1^{\dagger}$ & $56.98 \pm 5.09$ \\
IOC1113 & Reference strain & 1 & $70.79 \pm 21.65$ \\
S08-06 & Cat & $2^{\ddagger}$ & $141.90 \pm 33.56$ \\
S30-09 & Cat & 1 & $91.90 \pm 24.81$ \\
S34-09 & Cat & 1 & $115.87 \pm 11.58$ \\
H1 & Human & 2 & $168.25 \pm 23.57$ \\
H2 & Human & 1 & $109.36 \pm 22.17$ \\
H4 & Human & 1 & $98.25 \pm 24.45$ \\
S02-05 & Dog & 2 & $114.60 \pm 20.34$ \\
S10-06 & Dog & 2 & $169.05 \pm 26.71$ \\
S11-06 & Dog & 2 & $160.16 \pm 50.30$ \\
\hline
\end{tabular}

${ }^{\dagger} 1$ absence, ${ }^{\ddagger} 2$ presence

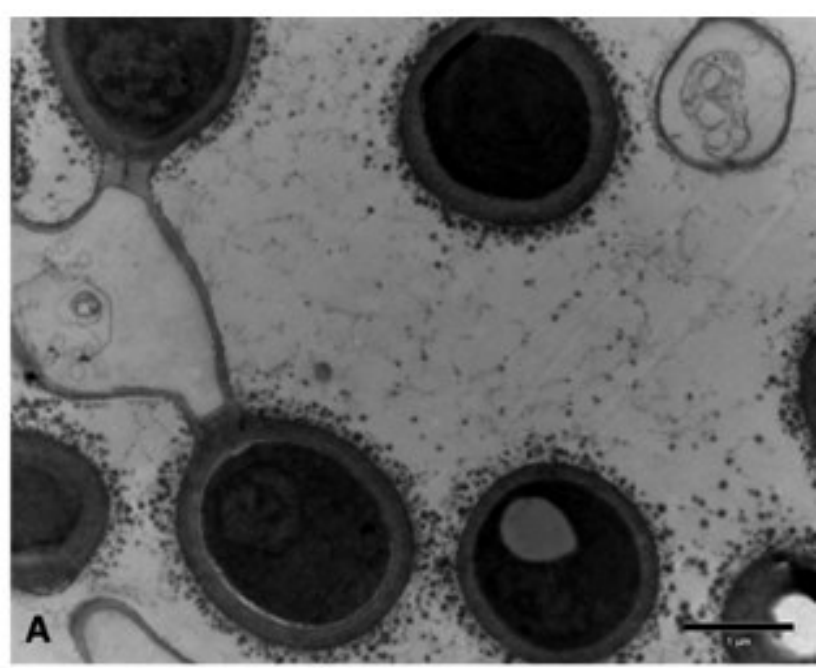




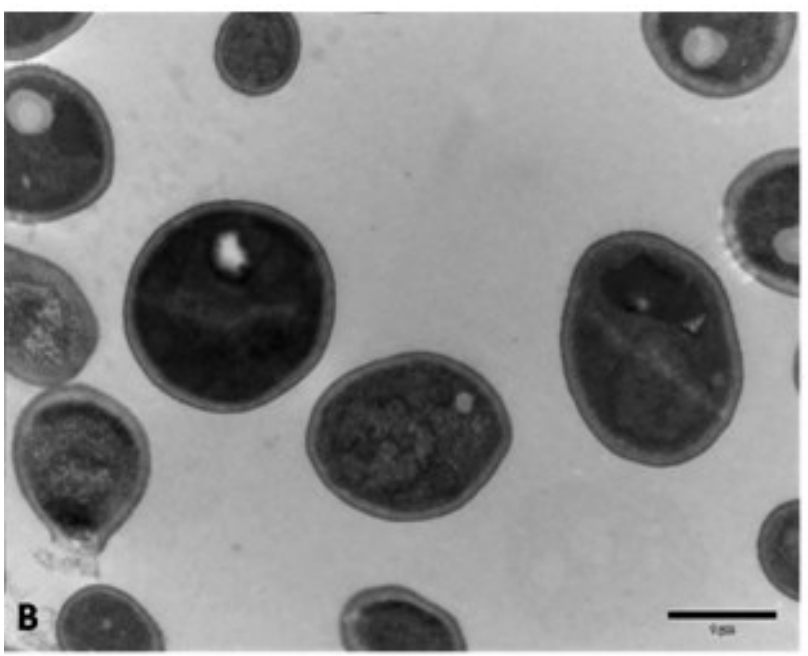

Figure 1. TEM images of $S$. schenckii cells with (a) and without (b) melanin granules. Scale bar: $1 \mu \mathrm{m}$

Table 2. Differences in cell wall thickness between $S$. schenckii isolates.

\begin{tabular}{cc}
\hline Clinical Isolates & Mean $\pm \mathbf{S D}(\mathbf{n m})$ \\
\hline Dog & $147.94 \pm 41.91^{\mathrm{A}}$ \\
Human & $125.29 \pm 38.59^{\mathrm{B}}$ \\
Reference strain & $63.89 \pm 17.03^{\mathrm{C}}$ \\
Cat & $116.56 \pm 32.07^{\mathrm{B}}$ \\
\hline
\end{tabular}

Fungal cells exhibited oval, round or pear shapes and variable sizes. The internal structures of the cells were similar, independent of the presence or absence of melanin granules.

The fungus Sporothrix schenckii is found in the form of hyphae and conidia in soil rich in decaying vegetation, sphagnum moss, grass and bark of trees. The survival of this fungus in the environment is determined by various factors, including the presence of melanin in the cell wall. This pigment is not essential for fungal growth and development, but can contribute to virulence of the pathogen $(1,2)$. Melanized S. schenckii cells have been shown to be less susceptible to death induced by ionizing irradiation or reactive oxygen and nitrogen species (14). In this work, we studied clinical isolates of $S$. schenckii with and without melanin around of the conidial cell wall. All isolates derived from canine sporotrichosis contained melanin granules; whereas, only one of the feline isolates and one of the human isolates exhibited this characteristic.

S. schenckii is known to produce dihydroxynaphthalene melanin by the pentaketide pathway. In vitro studies have shown that melanized cells are more resistant to phagocytosis and death caused by human monocytes or murine macrophages than mutant albino cells (14). In addition, in vivo studies have demonstrated differences in virulence between pigmented and albino mutant isolates of $S$. schenckii (12). Absence of electron dense granules has been demonstrated in a mutant albino strain of S. schenckii produced by means of exposition to UV radiation $\left(300 \mathrm{ergs} / \mathrm{mm}^{2}\right)$; conversely, the wild-type strain did exhibit granules in the external cell wall (11). Other ultrastructural studies on Sporothrix schenckii failed to detect a melanin layer in the external cell wall but found differences in cell wall thickness between the mycelial and yeast phases $(3,4,7)$. In the present study, the thickness of the cell wall of isolates devoid of melanin granules was smaller than that of isolates in which melanin was present. Therefore, higher cell wall thickness is directly connected to the presence of melanin. Consequently, presence of melanin and cell wall thickness interfere with the action of phagocytes and of antimicrobials. The results of the present study are in agreement with those of Mandal et al (9), who noticed that presence of melanin was directly proportional to the thickness of the cell wall in Cryptococcus neoformans isolates.

The research of virulence factors of the mycelia phase is important because the infection occurs by traumatic inoculation of conidia into the body (15). Our results demonstrate differences regarding presence melanin among Sporothrix schenckii isolates obtained from canine, feline and human cases of sporotrichosis and also a correlation between presence of melanin and cell wall thickness. 


\section{ACKNOWLEDGEMENTS}

The authors thank Conselho Nacional de Desenvolvimento Científico e Tecnológico (CNPq) by financing this research. To Simone Silveira da Silva for the technical support.

\section{REFERENCE}

1. Bell, A.A.; Wheeler, M.H. (1986). Biosynthesis and functions of fungal melanins. Annual Rev Phytopathol 24, 411-451.

2. Butler, M.J.; Day, A.W. (1998). Fungal melanins: a review. Can J Microbiol 44, 1115-1136.

3. Findlay, G.H.; Vismer, H.F.; Liebenberg, N.W. (1979). Spore ultrastructure in Sporothrix schenckii. Mycopathologia, 69, 167-170.

4. Garrison, R.G.; Boyd, K.S.; Mariat, F. (1975). Ultrastructural studies of the mycelium-to-yeast transformation of Sporothrix schenckii. J Bact 124, 959-968.

5. Hogan, L.H.; Klein, B.S.; Levitz, S.M. (1996). Virulence factors of medically important fungi. Clin Microbiol Rev 9(4), 469-488.

6. Jacobson, E.S. (2000).Pathogenic roles for fungal melanins. Clin Microbiol Rev 13, 708-717.

7. Lane, J.W.; Garrison, R.G.; Field, M.F. (1969). Ultrastructural studies in the yeastlike and mycelia phases of Spororichum schenckii. J Bact 100, 1010-1019.

8. $\quad$ Langfelder, K.; Streibel, M.; Jahn, B.; Haase, G.; Brakhage, A.A. (2003).
Biosynthesis of fungal melanins and their importance for human pathogenic fungi. Fungal Genetics and Biol 38, 143-158.

9. Mandal, P.; Roy, T.S.; Das, T.K.; Banerjee, U.; Xess, I.; Nosanchuk, J.D. (2007). Differences in the cell wall architecture of melanin lacking and melanin producing Cryptococcus neoformans clinical isolates from India: na electron microscopic study. Braz J Microb 38, 662-666.

10. Morris-Jones, R.; Youngchim, S.; Gomez, B.L.; Aisen, P.; Hay, R.J.; Nosanchuk, J.D.; Casadevall, A.; Hamilton, A.J. (2003). Synthesis of melanin-like pigments by Sporothrix schenckii in vitro and during mammalian infection. Infec Immun, 71, 4026-4033.

11. Nobre, M.O.; Antunes, T.A.; Meireles, M.C.A.; Ferreiro, L. (2004). Production and evaluation of albino mutants of Sporothrix schenckii. Acta Scient Veterinar 32(2), 119-123.

12. Nobre, M.O.; Madrid, I.M.; Antunes, T.A.; Martins, A.A.; Fernandes, C.G.; Mattei, A.S.; Spanamberg, A.; Meireles, M.C.A.; Ferreiro L. (2008). Virulence differences between albino and pigmented Sporothrix schenckii isolates. J Mycologie Médicale 18, 191-197.

13. Nosanchuk, J.D.; Casadevall, A. (2003). The contribution of melanin to microbial pathogenesis. Cell Microbiol 5, 203-223.

14. Romero-Martinez, R.; Wheeler, M.; Guerrero-Plata, A.; Rico, G.; Torres-Guerrero, H. (2000). Biosynthesis and functions of melanin in Sporothrix schenckii. Infect Immun 68, 3696-3703.

15. Schubach, T.M.; Schubach, A.; Reis, R.S.; Cuzzi-Maya, T.; Blanco, T.C.M.; Monteiro, D.F.; Barros, B.M.; Brustein, R.; Zancope-Oliveira, R.M.; Fialho-Monteiro, P.C.F.; Wanke, B. (2001). Sporothrix schenckii isolated from domestic cats with and without sporotrichosis in Rio de Janeiro, Brazil. Mycopathologia 153, 83-86.

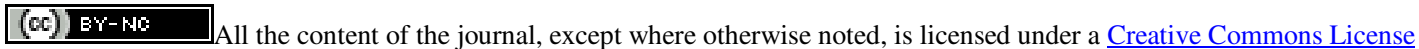

